European Journal of Tourism Research

http://ejtr.vumk.eu

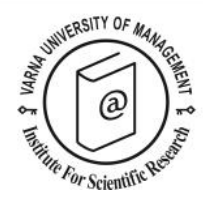

\title{
Dixit, S. K. (Ed.) (2020) The Routledge Handbook of Tourism Experience Management and Marketing: Routledge. Hardback. $65^{2}$ pages. ISBN 9780367196783
}

\author{
Reviewed by \\ Priyakrushna Mohanty ${ }^{1 *}$
}

${ }^{1}$ Department of Tourism Studies, School of Management, Pondicherry University, Puducherry, India. Email: pkmohanty9o@gmail.com

* Corresponding author

Citation: Mohanty, P. (2021). Book Review of Dixit, S. K. (Ed.) (2020) The Routledge Handbook of Tourism Experience Management and Marketing. Oxon: Routledge. European Journal of Tourism Research 27, 2712. 
At a time when the whole tourism industry is moving towards a demand-driven-experience-based market structure, Saurabh K. Dixit's handbook with 52 chapters authored by 83 contributors from 28 countries comes as a very timely, rigorous, and apposite addition to the body of tourism literature. The book discusses the various facets of creating, marketing, managing, and enhancing tourism experiences (TE hereafter) while exposing many recent developments and intersectionality in the area of tourism experience management (TEM hereafter). The handbook deliberates upon the concept of tourism experience management and marketing (TEMM hereafter) in six distinct sections that have been discussed below.

The first section of the book titled “Tourism experience: theories, structure, and frameworks" consists of ten chapters and provides in-depth insights into the underlying elements, key literature, and ongoing trends concerning TEM. The first chapter of this handbook highlights the underpinning concepts, theories, and definition of TEM while established typology in the area of TEM is discussed in the fourth chapter. Chapter 2 explores the key trends, methodologies, analysis techniques, and approaches used in the field of TEM research during the period of 2009-2018. Similarly, while Chapter 3 brings forth the push and pull motivations behind tourists traveling for experiences, Chapters 6 and 7 discuss the ways of measuring emotions and the importance of experiences in tourism respectively. Chapters 5 and 8 share the common aspect of customer experience. Chapter 5 provides an overview and critical aspects of customer experience while Chapter 8 defines the relationship between service employees and customer experiences. Chapter 9 analyses the dominant role of tourist experiences in shaping the future travel decisions of the tourists and the perceived image of the destination. The last chapter (10) of this section critically examines the idea of "experience economy" (introduced by Pine and Gilmore) and showcases its "limited utility" in defining tourism and allied phenomena.

Constituted by eleven chapters, the second section of the handbook titled "Crafting tourism experiences" underlines the various determinants, constructs, and factors associated with TE. Chapter 11 proposes a model for (experience) design process by citing a few examples and a case study. Taking cues from Chapter 1, Chapter 12 discusses the experience propositions created by tourism suppliers and the buyers while highlighting the different factors that can influence the tourist buying decision and experience design. Jon Sundbo, the common author in Chapters 1 and 12, extends his contribution to the book by providing insights about experiential dissonance in Chapter 21 where he creates a model for total experiences. Chapters 13, 14, and 19 throw light on the determinants and constructs of the TE. While Chapter 14 focuses on the role of destination image, perception, and motivation of tourists, Chapters 13 and 19 highlight the importance of servicescape (physical and social) and themes (and stories) on overall TE respectively. Chapter 15 talks about the usefulness of transformational and experiential learning theories in understanding extraordinary TE. Chapter 16 ponders upon the City Hospitality Experience Model and argues about how volunteer residents acting as city hosts can cocreate welcoming experiences and add value to the image of the residents as a welcoming community. Chapter 17 exhibits the value of design thinking in creating customer-centered experiences at the heritage tourism sites of the UAE. Chapter 18 elucidates the current trends in marketing strategies and experience designs applied by the wineries of Victoria, Australia to woo millennials. Chapter 20 reflects upon how embodiment and performativity can create lived tourist experiences by providing the instance of dog sledding experience in the Arctic.

The third section of the book (Crafting tourism experiences) includes ten Chapters and focuses on the Marketing approaches in the TEMM. The first chapter of the section, Chapter 22, talks about the paradigm shift of tourism marketing techniques from traditional to experimental approaches and Chapter 23 elaborates the impact of experiential marketing on tourist behaviour with the use of the 
Tourism behaviour framework. In Chapter 24, the Tourism Customer Engaging model is designed for analysing its association with customer experiences, brand identification, and loyalty while highlighting the implications for the tourism marketing academia and practitioners. Chapter 25 discusses the relation management as per the perspectives of customer experiences. Chapter 26 analysed the relationship between experiential tourists and perceived values, association among overall satisfaction, and loyalty for improved marketing, Chapter 27 sheds light on the strategic importance of memorable tourist experiences and delivery quality. Chapter 28 highlights the use of gastronomy experiences for branding and destination marketing. The next chapter (29) examines the association among product delivery for the promised response, customer subject response, and brand reputation. Chapter 30 talks about customer complaining behaviour and the way to recover or manage service failures. The last chapter (31) of the section portrays the concept of dark tourism and points out that motivation (in terms of TE) behind visiting dark tourism sites.

Titled as "Technology-enabled tourism experiences", the fourth section of the handbook consists of seven Chapters and underscores the aspect technology-driven interventions used for positively influencing and enhancing TE through active and passive engagement. The first chapter (32) of this section stresses the importance of creating favourable accommodation experience through the sharing economy which then can add towards the overall TE. Chapter 33 discusses the recent developments in the tourism industry (with special reference to ICT tools) that have an impact on TE at different stages of (pre, during, and post) traveller journey. By taking Germany and New Zealand as case studies, Chapter 34 beautifully portrays the growing role of digital media (like social networking sites) and digital narratives in co-creating TE. Similarly, Chapter 35 explores the nuanced role of ICT-driven tools in delivering lucid narratives that can co-construct encouraging impact on wine TE. Chapter 36 examines the role of visual experiences (especially in terms of colour) in moulding the buying decision making process with special reference to the websites of the UK. Chapter 37 (like Chapter 35) highlights the increasing value of social media in co-creating TE while citing the case of South Korea and the Value Co-creation Framework as the base of the work. Chapter 38 investigates into innovative tools like AR and VR in constructing passive immersive TE.

The fifth section of the handbook consists of five Chapters and is titled "Sustainable Tourism Experience". It deals with the issue of striking a balance between sustaining the visitor experiences and the integrity of the destination while projecting sustainability as a perennial element in creating TE. Chapter 39 puts forward the argument that a well-conceived and neatly designed TE plan not just create better TE but can also make the destination sustainable. Chapter 40 ventures into the idea of viewing sustainable tourism from the identity decomposition angle and elucidates how TE must be integrated with the identity of the place. Citing the case study of Kota Belud, Sabah in Malaysia, Chapter 41 elucidates how co-creation of rural-based experiential products can develop the prospects of rural tourism and achieve sustainable tourism experiences. Chapter 42 derives the relationship existing between green loyalty and other constructs like green emotional attachment, green experiential quality, green switching experience, green image, and green experiential satisfaction. Chapter 43 places its focus on the growing concern of managing the guest-host relationship and concludes that it's not just the experiences of tourists but also the experiences, values and perceptions of the other stakeholders that matter in making a destination sustainable.

The last section of the book titled "Emerging avenues of tourism experience and co-creation" consists of nine chapters and provides accounts of the emerging aspects, concepts, and issues in the field of TEM. The first chapter (44) of the last section of the handbook depicts a model for the system of cocreation and describes how the system works from a holistic view. Chapter 45 explores the aspect of TE 
co-creation by service-dominant logic developed by Vargo and Lusch (2004). Citing the case of Albergo Diffuso, an Italian hospitality model, Chapter 46 highlights the ability of the Place-Based Business Model in organizing the resources of a firm and ultimately create value. Chapter 47 talks about the cultural concept Chinese "face" (a particular set of behaviour or custom) of an increasing number of Asian/Chinese tourists visiting the arctic region and the need to co-create TE at the arctic region. Chapter 48 explores the interesting aspect of the value of emotional labour while co-creating TE in the context of the sharing economy and Airbnb in particular. Chapters 49 and 51 connect the concept of destination competitiveness and crisis management with TE while bringing up fascinating findings. Chapter 50 deals with investigates the niche of TEM for senior tourism and traces out huge potentials that lie ahead. Lastly, Saurabh K. Dixit notes his further reflections about TEMM in Chapter 52.

The key point of the book is its extensive coverage in terms of representations (case studies) from the global east and the west. However, the absence of representation from the African continent is one aspect that may be considered in the editors' forthcoming works. Also, the inclusion of Chapter 46 (Place-based business models of value creation in tourism) with little links with TEM along with the presence of chapters with similar objectives (with different approaches and case studies) like Chapters 35 and 37 were decisions that the reviewer found hard to fathom. But these critical notes can also be the reviewer's thoughts and should in no way devalue the extraordinary contribution that the book makes to the body of TEMM literature. All in all, the magnanimity of the book lies in the depth of literature it cites and carries forward while examining the doctrine of TEMM; the right mix of past, present, and future. There is no doubt that the book would a resourceful material across the students, researchers, and practitioners' community.

Received: 27/08/2020

Accepted: 04/o9/2020

Coordinating editor: Stanislav Ivanov 